\title{
COMMUNITY OF PRACTICE AS ONE OF THE COMPETITIVE ADVANTAGE OF ORGANIZATION
}

\author{
Veronica; Angellia Debora Suryawan \\ Information Systems Department, School of Information Systems, Bina Nusantara University \\ Jl. K. H. Syahdan No-9, Jakarta 11480, Indonesia \\ veronica@binus.edu; asuryawan@binus.edu
}

\begin{abstract}
Many organizations in the world realize that to maintain the stability of an organization within a lot of turnover in human resources, Knowledge Management (KM) is a matter that cannot be forgotten. Since by storing the knowledge, organizations can continue to distribute the knowledge to people and to develop it into a practice of learning, problem solving, and then at the end it becomes a "Best Practice". Sharing knowledge becomes the main reference in $\mathrm{KM}$ in large and small organizations. By multiplying the activities of knowledge sharing among employees in an organization, it can improve the competitiveness of the organization. All activities in knowledge sharing will be easier if it is formed in a Community of Practice (CoP). CoP can be regarded as a best method. In addition there are many benefits that can be spawned by it, such as in the development, dissemination of knowledge to the development of culture in an organization. The method in this paper uses literature study by describing best practices and case studies in a private bank in Indonesia. By forming the CoP, it is expected to motivate employees to share knowledge for the improvement of organizational performance.
\end{abstract}

Keywords: organization, knowledge management, community of practice

\section{INTRODUCTION}

Today the business practitioners often ask questions about how to build organizational excellence in various sectors. Some of them believe that the organization's ability to understand the changes in the competitive environment in an industry and then be responded to the proportion of the value or range of placement options in a value chain will determine the final performance of the organization. According to Ref. [1], a good and superior company is capable in building a sustainable competitive advantage in their respective industries, both in the context accepted by the market and in the context of financial performance that deliver value to stakeholders. Meanwhile, according to Ref. [2], companies that have a competitive advantage is the company that can surpass their competitors in their respective industries. Furthermore, the superior performance of the company should be sustainable and can survive in a specific time period.

Reference[3] conducted a research on over 200 years old organizations and found that the general characteristics of the cause of short-surviving-period of the companies are mainly because the companies are not able to learn or adjust themselves to the demands in the changing times. The companies then disappointed the consumer and eventually could not survive due to loss of market share or being rejected by consumer and the environment. But in fact, there are some cases where some companies have a long life (over 150 years). Reference[3] describes the phenomenon of long-surviving-period companies as a company with the characteristics of living. Reference[3] stated that there is a correlation between long-surviving-period company with the ability to become a learning organization. The facts that many organizations cannot survive in a long period of time means that many organizations are not able to learn.

The large number of smart human resources within an organization does not mean that the resources are able to build a smart organization and make the organization lives long. Organizations must be able to have a working environment as well as a mechanism to encourage its human resources in creating knowledge explicitly or implicitly and triggering an innovation to maximize the added value of the organization.

One of the activities mentioned in $\mathrm{KM}$ is to maximize the Community of Practice (CoP) in an organization. This activity aims to collect and share knowledge from one person to another person in the organization so that it can create continuous learning to improve profits in the organization.

This CoP has a goal to be able to capture, filter and manage all information/knowledge of individuals (tacit knowledge) in organization that is acquired 
in the activities of problem-solving in the business process. The problems are to be solved together and redisseminated in order to become common knowledge (explicit knowledge). In addition $\mathrm{CoP}$ also can be used as a medium for development (improvement) of knowledge, so it can create another "best-practice" which is very helpful in business operations.

\section{METHOD}

This research method uses literature study to get the related theories and supporting the writing of this article. Literature study materials obtained from journals, articles, books, and other reference that supports the processing and analysis of data. Additionally, literature study on previous research is conducted to obtain the required information.

In addition to the study of literature, a visit to the object and interviews in three parts in a private bank in Indonesia is carried out. Questions of interview are submitted to the IT, Business Support and Marketing Support. Interview is conducted by asking a few questions related to the implementation of the CoP so getting a final conclusion regarding the implementation of the CoP.

\section{Literature Review}

According to Ref. [4], communities of practice $(\mathrm{CoP})$ has been increasing in popularity as a way to manage the human and social aspects of the creation of knowledge (knowledge creation) and its spread in the organization, also has received critical attention in the literature of knowledge management. "Community of Practice is a community made up of a group of people, who have the same desire for something they're working on, and interact regularly to learn together to help their work is"[5].

The term of community of practice created by Ref. [6] which defines it as “... an activity system of participants share understandings about roomates concering what they are doing and what that means in Reviews their lives and for Reviews their community". A newcomer to initially perform "peripheral" or modest activity in completing a specific task, and over the time he/she will accept the role and heavier duty so quickly he/she will become an expert (expert). This is a learning process by entering the "legitimate peripheral participation".

Research on CoP finds that the most occurring interactions is in the informal discussions, faceto-face, where the members familiarize to discuss related issues [5]. During this informal interaction, the member of CoP perform all three cognitive processes, that are narration, collaboration, and social construction [7], and in its development, it is carried out by means of shared among the members of which each has a memory attached to each member. The memory of this community will maintain the relevant knowledge to practice in the field and the ability to interpret [8].
One common assumption in the literature is said that there is a positive relationship between the $\mathrm{CoP}$ and performance, either individual, groups and organizations. One is the basis is an assumption from widely-held, which believes believe that the transfer of tacit knowledge and the learning of a leader can improve performance. In the original research, it appears that the development of the $\mathrm{CoP}$ is based on the learning theory situation although it argues the learning through participation in activities Sharing [6].

Although the term CoP is still relatively new, this activity is not new. A group of people who share knowledge in an organization has existed since knowing the benefits of sharing knowledge, insights and experiences with others who have the same interests or goals.

According to Ref. [9], there are three important characters are needed in building Community of Practice: (1) The Domain, a Community of Practice is not just a club of friends or a group of people that are gathered. However, what distinguishes Community of Practice is they are talking about a domain/theme that they consider/prefer. So that the objectives of someone's who joined the Community are clear, they are committed to help in building knowledge of a domain in the community, (2) The members of the Community of Practice, in pursuit their preferred domain, are expected to involve actively in activities and discussions, help each other, and share information by becoming practitioners. They build relationships that enable them to learn from each other. Community of Practice not only needs a group of people who have the same preferences, but Community of Practice also needs these people to share their knowledge, learn and teach. Without all the activities, the community was just a regular community,(3) The Practice, all members of the Community of Practice is a practitioner, so hopefully they are able to share and continue to develop a knowledge into a "Best Practice" from various sources, such as experiences, stories, what tools are needed, and how the settlement of a problem. In building this "Best Practice", it takes time and sustained interaction.

Community of Practice is considered unique. It has many unexpected advantages that cannot be found in other Knowledge Management process. There are several reasons why the Community of Practice is considered unique.

1. Building knowledge into "Best Practice".

Since the members of Community of Practice are practitioners, in other words people who have entered the workforce, so that they would become a contributor who will bring a lot of ideas and new ideas to build the knowledge to become a best practice.

2. Improving the quality of knowledge and 
implementation in the future.

Discussion process in the Community of Practice not only can improve the quality of the knowledge to be better, but also ensure the implementation process to run perfectly.

3. Knowledge well-targeted at real problems

For the same reason, because of these practitioners, the focus of the Community of Practice is the use of knowledge in problem solving that can be used directly in the work of the organization

4. Allow the emergence of new innovations

Community of Practice is not limited to the knowledge that is given, it is not impossible if at the time of the development of such knowledge would appear the new knowledge that can be developed by its members.

5. Encourage the interest of members in becoming active in teaching and learning

In a Community of Practice will appear many contributors to the knowledge, and this will influence others to do the same, so it will build a culture of learning and teaching.

6. Efficient

Community of Practice will not require a lot of cost and effort, since when the Community of Practice is running, then there will be the eagerness of its members to continue to support this Community.

7. Self Learning

In contrast to other methods of dissemination of knowledge, in the Community of Practice every member can ask other members (not teachers) who already understand the knowledge. So the teachers' availability are not so necessary anymore.

8. Building Relationships

Community of Practice can build better relations among its members, this is because the equations of their interest and knowledge to discuss the activities they always discussed together.

9. Character Development

In addition to developing discussed knowledge, Community of Practice will also develop the personality of its members (Character Building) through the learning process, so that the organization will also benefit from this.

10. Revisiting the talents of each member Community of Practice will open the talent/ knowledge/practices are held in secret by the members of the organization. This will further enrich the knowledge of the organization. In addition to the disclosure of the talent/ knowledge/practice owned by the members of the organization, the organization has a beneficial because it can use the resource of the existing membership.

11. Building a positive culture within the organization

When viewed from the side of the organization, Community of Practice can also build culturepositive culture of the members are required to build a strong and productive organization.

\section{Designing and Building a Community of Practice}

In designing and building a Community of Practice, the model 5D can be used [10], namely:

1. Discovery

Relationship exploration with the organization through individual narratives, this stage is the initial interaction between members by telling about themselves. There are a few things that is needed to consider such as background of the members, knowledge (knowledge / practice) that they have, their purpose in the organization and their expectations in the organization, etc.

2. Dreaming

This stage is the stage of combining the things that have been found in the Discovery into the same vision/goals that support the development of Organization's Knowledge Management by creating the same vision/goals that is expected to create a strong community since they have the same goal.

3. Design

Having obtained the goals to be achieved, at this stage, the design and development of operational processes of what is to be achieved is started to be done (From dreams toreality). At this stage, there will be discussion of knowledge, knowledge relationships with each member's work, the role of each member in the organization, technology and necessary infrastructure to ensure that knowledge can be created, shared and documented.

4. Document

At this stage, the community will be allowed to learn and grow. Depending on the earlier stages, members of the organization will begin to discuss either directly or indirectly (through a variety of online media for example), or held a brief meeting to discuss the knowledge. This phase will begin to open up the eyes of the other members who were previously less interested. Then, along with the development of knowledge, other members who are less active will start to be interested in participating in a Community of Practice. If this continues to be maintained then it is not impossible that the process will be quickly resolved. Managerial job at this stage is to perform monitoring and documentation of all their learning outcomes. Carry out documentation as detailed as possible and do anything that can be documented, for example in the form of documents, files, pictures of events, posters, records the results of 
the meeting and others.

5. Disseminate

Phase dissemination/socialization has two core phases, first, routinelydoing everything necessary to disseminate documentation to all members of the organization who need it. Second is creating a face-to-face meeting on a regular basis to discuss what has been organizational members learned and share with other members. At this stage there will be a new social relationships between the members and it will build the future of the organization.

\section{RESULTS AND DISCUSSION}

\section{Application of Community of Practice (CoP)}

The growth of banking in Indonesia tends to be high. Many new and emerging banking companies that create the banking competition is getting tougher. All banks are vying with each other to provide services and promotional products that are expected to satisfy the consumer to remain loyal to the bank. As a result of this competition makes one private bank in Indonesia (Bank XYZ) to continue to develop its strategy. XYZ Bank has been implementing the concept of Knowledge Management (KM). The concept of $\mathrm{KM}$ is incorporated into business strategy so that all employees can support XYZ Bank to support the vision, mission, and values espoused.

As a company that is relatively large in Indonesia, Bank XYZ has relatively many employees. It has branch offices throughout Indonesia. Large organizations have weak internal communication practices than smaller organizations because of job specialization and functional separation has reduced access to information about the service provided. In other words, small organizations have a greater assurance of effective internal communication practices. Distribution of information about the company can not depend only on word of mouth alone. Employees need to know what is happening in the company so well-informed, prior to external parties know about the information.

Therefore, XYZ Bank has a unit called the Learning Center. This is where all employees, whether they are new or existing, learn and gain knowledge about XYZ Bank and other information needs. In a period of 1 year, the Learning Center can be organized around 2,000 classes with about 60,000 participants. From the Learning Center, this is the forerunner of knowledge sharing are encouraged to do in each unit. CoP program is run on each unit so that business and social interaction among employees.

Learning Center monitors a wide range of topics discussed on the CoP to ensure that it operates as intended. CoP is becoming more important for the functioning of an organization that values knowledge as a key asset. Knowledge created from each task performed by each employee in an organization, it can be distributed, recorded, reviewed and passed on within and among communities.

According to the results of interviews and observations that were done, the CoP at XYZ Bank fulfills a number of functions and the positive side of the creation, collection, and dissemination of knowledge within an organization

CoP help in building some of the positives sides: self-learning, creating innovations in work, creating an environment that is willing to learn, build strong relationships within the organization as well as strengthen the leadership.

$\mathrm{CoP}$ is a way to exchange and interprete information. Since the employees in a unit have a shared understanding, they know what is relevant to be communicated and how to present information in a useful way. As a consequence, a CoP that is spread in an organization is an ideal channel for moving information, such as best practices (best practices), tips, or feedback in a cross-organization.

$\mathrm{CoP}$ can retain knowledge in a way that is "live", not as a database or manually. CoP maintain aspects of tacit knowledge that the formal system cannot "catch". Therefore, the CoP is ideal for initiating newcomers into a practice.

The CoP members discuss new ideas, collaborate on issues, and keep the developments inside and outside the organization. Thus, members of the CoP can build innovations in their work and are not directly motivate them to work better. It can help an organization to have a strong relationship with its employees.

CoP helps employees to hone a sense of confidence in the members who do the teaching. This happens since in teaching-learning process the feeling of becoming needed and trust is growing. Additionally, it will also foster a sense of leadership itself. Confidence and leadership are to lead the members in the implementation of knowledge in the organization.

CoP can help the learning process as well as the organization because it has the ability to:

1. Answering questions

Community of Practice offers the opportunity to ask indefinitely, as long as the community is still running, member can freely ask to the expertise at anyplace and anytime.

2. Discussion group

Community of Practice offers a means of discussion groups. The discussion group enables the members to do the self-learning and developing further knowledge

3. Ask the expert

In a Community of Practice, the members of the organization can ask questions directly to people who has been engaged in the field directly without time limit. 
4. Adding motivation in learning

There are times when the members lose motivation when he/she has to learn the knowledge alone. However, this will not happen in the live community of practice since live Community of Practice has members who constantly growing, this will motivate all members to continue to learn and grow.

5. Ensure the correct thinking Wrong thinking about knowledge may lead into a serious impact in an organization. In a Community of Practice, each member is encouraged to be active in his/her opinion, if the opinion of the members is not right, then there will be other people/expert will fix the opinion. So, there is no wrong in thinking in knowledge

\section{CONCLUSION}

A developing organization will always add its capacity in knowledge, but there are many organizations that have not been aware of the need to regulate and organize knowledge in an organized manner, then it is required Knowledge Management. Knowledge Management is based on the willingness of all elements of human resources for sharing knowledge so that the continuous learning within an organization can sustainably occurs. One way to organize the sharing of knowledge is to establish a community of practice.

Similarly at XYZ Bank that has applied Community of Practice (CoP) in its business strategy. $\mathrm{CoP}$ is a group of people who have the same concern and passion about what they do and learn to do it better as they interact regularly. CoP can be said to be unique because it has many advantages that are not owned by the other methods. In building CoP,people need to pay attention to interested members, the expertise, and knowledge that will be built. In making and build knowledge, the technique 5D can be used, namely Discocery, Dream, Design, Document and Disseminate. The use of online technologies need to be considered as flexible and many other advantages. CoP concept refers to the process of social learning that occurs when people who have the same interest in some case or problem collaborate to share ideas, find solutions, and make innovations.

CoP has many constraints, such as time, the dependence of the results on the members, the difficulty of finding the right expertise and the process is only temporary. However, it is not so significant constraint since it can be easily overcome by the organization.

Management itself has a decisive role in starting the domain knowledge, encouraging members' and expertise's interest, monitoring and directing the activities and documenting the results of the CoP discussion.

With the fulfillment of the functions in the creation, collection, and dissemination of knowledge within an organization through the $\mathrm{CoP}$, it indicates that the CoP is one effective way of sharing knowledge that will ultimately improve organizational performance. With the CoP, it is expected to facilitate the learning process, the spread of knowledge can continue to run, and the process can be run and developed in a sustainable knowledge within the organization.

\section{REFERENCES}

[1] S. Haykin, Neural Network A Comprehensive Foundation, New York: Macmillan College Publishing Company, 2004.

[1] J. Kay, Foundations of Corporate Success, Oxford University Pers, New York, 1993

[2] M. A. Hitt, R. D. Ireland dan R. Hoskisson, Strategic Management: Competitiveness and Globalization, International Student Edition. South-Western. USA: Thomson Corporation, 2005.

[3] A. De Geus, The Living Company, Harvard Business School Press, 1997.

[4] A. Ardichvili, M. Maurer, W. Li, and T. Wentling, "Cultural Influences on Knowledge Sharing Through Online Communities of Practice", Journal of Knowledge Management, vol. 10, no. 1 2006, pp. 94-107, 2006.

[5] E. Wenger, "Communities of Practice: Learning as A Social System". The Systems Thinker, Vol. 9, No. 5, 1998.

[6] YJ. Lave, E. Wenger, Situated Learning: Legitimate Peripheral Participation, Cambridge: Cambridge University Press, 1991.

[7] J. S. Brown and P. Duguid, "Organizational Learning and Communities of Practice: Toward a Unified View of Working, Learning and Innovation”. Organization Science, vol. 2, No. 1, pp. 40-57, 1991.

[8] R. J. Boland, and R.V. Tenkasi, "Perspective Making and Perspective Taking in Communities of Knowing," Organization Science vol. 6, No 4, pp. 350-372, 1995.

[9] F. Nickols, "Communities of practice: An Overview". Distance Consulting, accessed on 01 Februari 2012, at http://home.att.net/ discon/KM/CoPOverview. pdf, 2003.

[10] E. Wenger, Communities of Practice: A Brief introduction, accessed on 01 Februari 2012, at http:// www.ewenger.com/theory/index.html, 2006 